\title{
Ranking and Evaluating the ARL Library Map Collections
}

\section{Charles A. Seavey}

This study measures and analyzes the map collections of the Association of Research Libraries (ARL) using data from 1984 and 1988. The nature of the cartographic format means that the size of a map collection can, within limits, be viewed as a measure of information content. Problems with the collected map data are noted. Size of collections and growth rates are computed and elements of change noted. A composite index, based on size and growth figures, is developed and used to rank the ARL map collections. Cartographic collection ranks are compared to ARL library index ranks and found to have a weak correlation. Directions for future research are suggested.

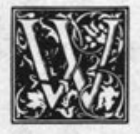

ilmer L. Hall has suggested that "Maps are often the stepchildren of libraries, receiving some attention at christening, but neglected henceforth."' ' $n$ one sense this statement is true. The map does not fit on conventional library shelving, does not convey information in textual format, does not conveniently fit into any cataloging code (present or past), is rarely treated as a topic in library schools, and often appears to be a vexatious problem to the harried library administrator. Yet the map is an invaluable medium of communication, often imparting in a single glance information that would require hours of reading ${ }^{2} \mathrm{Re}-$ gardless of the problems, academic libraries have long engaged in collecting and organizing maps, and today a collection of materials in the cartographic format is common in many academic libraries. ${ }^{3}$

This article tests the hypothesis that map collections are stepchildren within Association of Research Library (ARL) institutions. Of course, no precise defini- tion of Hall's characterization of map collections as "stepchildren" is possible. However, for the purposes of this investigation, it is assumed that if cartographic collections are stepchildren, then the ARL libraries will not expend the same amount of effort on collecting cartographic materials as they do on collecting other formats. The assumption leads to the statement: If the ARL libraries place equal emphasis on collecting both cartographic material and noncartographic material, then rank-orders for both types of collections should be the same.

In general, academic libraries have done little in the way of measuring or evaluating, in any quantitative sense, their collections of cartographic materials (here defined as maps, aerial photography, and remote sensing imagery). The ARL collects data on book, serials, and microform holdings but does not gather data for maps or other cartographic formats. Hence neither researchers nor library administrators have much in the way of data, let alone agreed-upon norms on which to base possible methods

Charles A. Seavey is Assistant Professor at the Graduate Library School at the University of Arizona, Tucson, AZ 85719. 
of evaluation for map collections.

While the literature includes descriptions of individual map collections, or portions thereof, few studies attempt an overall description or analysis of more than one collection. Stanley D. Stevens surveyed twenty-six predominantly academic map collections in the western United States. His analysis dealt largely with personnel issues, although it did include some general observations on collections. ${ }^{4}$ David A. Cobb provided the first attempt to analyze the upper echelons of map collections in this country. ${ }^{5}$ His analysis was descriptive in nature and limited to the largest map collections in various categories. The second edition of the Guide to U.S. Map Resources contains a similar analysis. ${ }^{6}$ Beyond these first analyses no significant attempts to compare map collections exist.

The present study measures ARL map collections. This study assumes that size of collection is a strong indicator of the information content of the collection. A long-standing, almost unspoken, assumption in libraries is that a collection with more information content is of higher quality than one with lower information content. This assumption needs further explication.

The notion that collection size equals quality is implicit in the ARL library index and is discussed in the data section of this article. Widespread anecdotal evidence indicates that most librarians equate collection size with collection quality. Susan A. Cady flatly states, "The quality of a research library is still measured primarily by the size of its holdings" (italics in the original). ${ }^{7}$

The equation of size with quality has come under a great deal of scrutiny in recent years. In A Planning Process for Public Libraries and in Output Measures for Public Libraries, the Public Library Association (PLA) has specifically rejected the notion. ${ }^{8}$ The Association of College and Research Libraries (ACRL), in Measuring Academic Library Performance, has produced a system conceptually similar, in many ways, to that of the Public Library Association.' The Association of Research Libraries, however, still bases its measures and rankings largely on size of the collections being measured. ${ }^{10}$

In the context of large research libraries, the argument can be made that size of book and serial collections equals information content and quality. Undeniably, larger collections contain more information than smaller ones. While the ARL measures, when compared with the PLA and ACRL methods, are simplistic in terms of library interaction with its user community, they do, in a fashion, address the notion of what a research library is all about.

In evaluating a collection of cartographic materials, the argument that size of collection equals information content is even stronger than a similar argument involving books and serials. Cartographic items are unique, or nearly so, in their information content. The size of most cartographic collections is largely determined by their holdings of large-scale topographic maps. It requires, for instance, 57,401 individual maps to cover the contiguous 48 states of the United States in the standard series of U.S. Geological Survey (USGS) 1:24,000 topographic quadrangles. USGS has map series at 1:50,000, 1:100,000, 1:250,000, 1:500,000, and 1:1,000,000 that either will, or do, cover the entire United States. Virtually all other nations have mapping projects employing a similar, or greater, range of scales. Such topographic maps are often used as base maps for thematic maps, such as soil or geologic maps, which are available at various levels of scale, or generalization."

Each topographic map is a unique item. If the user desires a large-scale topographic map of an area in northwest Albuquerque, New Mexico, there is only one choice. ${ }^{12}$ No alternative interpretations of the same body of information exist. A map, unlike subjects presented in book or article form, does not have a Marxist, or deconstructionist, or feminist alternative explanation. Maps can differ in scale or time of situation, but those features are also items of unique information content. While thematic, or subject, maps will occasionally have alternative explanations, these are in the minority. The 
great bulk of cartographic items (topographic maps, or thematic maps based on topographic quadrangles) in a given collection are, therefore, unique and complete additions to the information content of the collection. Other information formats present overlapping amounts of information content. The unique contribution of an individual book to the knowledge base is considerably less than the contribution of an individual map.

Therefore, the claim that larger map collections contain, in absolute terms and assuming little or no duplication, more information content than do smaller ones is valid. A study that ranks cartographic collections according to variables associated with sizeand growth figurescan provide some comparative data about cartographic information content within the ARL libraries. Within the context of the ARL libraries, if one accepts the idea that higher information content equals a higher-quality collection, then quality can be measured.

\section{THE DATA}

The ARL, as noted above, does not collect data on cartographic holdings. However, the Map and Geography Round Table (MAGERT) of the American Library Association (ALA) has produced two editions of the Guide to U.S. Map Resources, in 1986 and $1990 .{ }^{13}$ The data presented are for calendar years 1984 and 1989, respectively. Preparations for the first edition of the Guide started in 1983 and involved a large group of expert map librarians. ${ }^{14}$ The data-collection instrument went through several drafts. ${ }^{15}$ As data were collected, they were subject to review from a group of nineteen regional editors, chosen for their knowledge of their respective areas, and a final review by the compiler of the Guide. This process was repeated for the second edition. While no data-collection process is perfect, the data are sufficiently reliable for the variables and methodology employed in this study. Where weaknesses exist, they are in the original data reported by the various map collections. For example, size of collection (sheet count) is often expressed in figures ending in four or five zeroes (e.g., 40,000 or
200,000) which implies less-than-precise knowledge on the part of the reporting collection.

\section{THE POPULATION}

The cartographic holdings of eightyeight ARL libraries were considered. The ARL population is actually higher, but the Guide does not report data on Canadian institutions. Further, some American institutions reported no data, and two collections (Howard and Georgetown) are so atypical that they were removed from the study. ${ }^{16}$ The eighty-eight ARL libraries in this study have among them 169 map collections. All collections associated with a given institution were counted on the assumption that they were all open for use by the libraries' public. Cartographic collections are often separated. Typically there might be collections in the main library, a geology or science collection, and a historical collection.

\section{VARIABLES COLLECTED}

The following variables were extracted from the two editions of the Guide.

1. Total sheet count. Traditionally, map collections have been counted by the number of individual map sheets held in the collection. While numerous maps are parts of sets, or series, individual sheets form separate bibliographic and information-bearing entities. Counting individual sheets does not address issues of multiple-copy teaching sets (which are in the collection at Louisiana State University, for instance) or the geographic areas covered by the collection.

2. Total count of aerial photographs. Aerial photography is both the basis for much map making and heavily used as a supplemental information source in map collections. A considerable amount of time can pass between editions of topographic maps for rural and lightly populated areas. Aerial photography is often available from various sources much more frequently. While some overlap exists among adjacent aerial photographs, this duplication is necessary for 
TABLE 1

RANK, BY SIZE OF MAP COLLECTION, 1989

\begin{tabular}{|c|c|c|c|}
\hline \multicolumn{2}{|l|}{ Top Twenty } & \multicolumn{2}{|l|}{ Bottom Twenty } \\
\hline University & No. of Maps & University & No. of Maps \\
\hline UCLA & 700,780 & Iowa State University & 91,033 \\
\hline Harvard & 520,000 & Washington University (St. Louis) & 89,112 \\
\hline Indiana University & 510,575 & Temple University & 88,450 \\
\hline U.C. Berkeley & 489,985 & University of Pittsburgh & 86,457 \\
\hline University of Illinois, Urbana & 444,774 & Mass. Institute of Technology & 83,004 \\
\hline Louisiana State University & 402,200 & Brown University & 75,000 \\
\hline Yale & 385,500 & University of Cincinnati & 74,930 \\
\hline U.C. Santa Barbara & 375,000 & Colorado State University & 34,799 \\
\hline University of Florida & 373,854 & Case Western Reserve University & 32,500 \\
\hline University of Tennessee & 359,199 & U.C. Riverside & 30,000 \\
\hline Pennsylvania State University & 336,000 & North Carolina State University & 24,230 \\
\hline University of Chicago & 330,100 & Wayne State University & 22,000 \\
\hline University of Georgia & 326,850 & Rice University & 21,000 \\
\hline University of Texas, Austin & 323,163 & Miami University & 17,621 \\
\hline University of Minnesota & 319,123 & Tulane University & 15,000 \\
\hline Princeton University & 290,914 & Washington State University & 15,000 \\
\hline Kansas University & 281,048 & Boston University & 10,500 \\
\hline University of Michigan & 242,900 & University of Southern California & 8,500 \\
\hline University of Washington & 232,426 & Rutgers & 3,150 \\
\hline University of Oregon & 230,000 & U.C. Irvine & 660 \\
\hline
\end{tabular}

Mean $=177,303$

STD $=132,548$

detailed interpretation of the information presented. Each photograph, therefore, is counted as a separate information-bearing item, although the bibliographic picture is considerably more confused.

3. Total count of remote sensing images. Data on holdings in remote sensing imagery were collected from the 1990 edition of the Guide only. The earlier edition had not collected data on remote sensing imagery. Remote sensing imagery is just starting to become available to the ARL libraries and represents a new field of cartographic information. The current convention follows the model established in counting aerial photography: each image is a separate information-bearing item.

\section{DATA MANIPULATION}

The data were entered onto creation sheets and then transferred to the Quattro Pro spreadsheet program, which was used for all further data analysis. An initial printout was reviewed and various anomalies identified. Where anomalies existed, correspondence was initiated to ascertain the cause of the problem. Problems encountered included:

1. Decrease in the size of the collection. All institutions showing a decrease werecontacted for explanations. The decreases, in general, may be attributed to two causes. First, multiple collections were consolidated between the two editions of the Guide, and the institution eliminated duplicate copies. Boston University, 
TABLE 2

RANK, BY INCREASE IN MAP HOLDINGS, 1984-89

\begin{tabular}{lrlr}
\hline \multicolumn{1}{c}{ Top Twenty } & & & \multicolumn{2}{c}{ Bottom Twenty } \\
University & Growth & University & Growth \\
\hline University of Texas, Austin & 116,163 & University of Southern California & 1,000 \\
University of Tennessee & 101,753 & Rutgers University & 650 \\
UCLA & 94,233 & U.C. Irvine & 60 \\
University of Illinois, Urbana & 83,044 & Columbia University & 0 \\
University of Maryland & 80,500 & University of Oklahoma & 0 \\
U.C. Santa Barbara & 75,000 & Vanderbilt University & 0 \\
University of Alabama & 63,800 & Boston University & $-1,500$ \\
U.C. Berkeley & 56,415 & University of Colorado & $-5,201$ \\
University of Chicago & 55,100 & SUNY Albany & $-8,000$ \\
Duke University & 52,900 & Virginia Polytechnic & $-9,900$ \\
University of Arizona & 50,437 & University of Virginia & $-11,750$ \\
Emory University & 50,000 & University of Michigan & $-17,100$ \\
Texas A\&M & 48,792 & Case Western Reserve & $-17,500$ \\
University of Connecticut & 47,000 & Wayne State University & $-20,000$ \\
U.C. San Diego & 45,000 & Ohio State University & $-22,461$ \\
Pennsylvania State University & 41,000 & Washington State University & $-25,000$ \\
S. Illinois University & 40,253 & University of Cincinnati & $-35,070$ \\
Cornell University & 38,400 & University of Oklahoma & $-54,820$ \\
Kansas University & 37,716 & Princeton University & $-66,086$ \\
University of Florida & 37,469 & Louisiana State University & $-99,300$ \\
\hline Mean = & & &
\end{tabular}

Mean $=18,766$

$\mathrm{STD}=32,500$

for instance, consolidated three collections into two, eliminating duplication and decreasing their total sheet count. Second, the institution counted their collection and discovered it to be somewhat smaller than the previously estimated figure. ${ }^{17}$

2. Growth rates that appeared to be far beyond normal expectations. Some of the growth can be explained by better data collection. The 1990 Guide lists more collections for the University of Texas at Austin than the 1986 edition. Part of the University of Tennessee's increase derives from consolidating the old geography department collection into the new main library there.

\section{DESCRIPTIVE RESULTS}

After gathering the supplemental information and correcting the spreadsheet, institutions were ranked according to the following variables.

1. Total map sheet count, 1991

2. Absolute increase in map sheet count, 1984-1989

3. Percentage increase in map sheet count, 1984-1989

4. Total cartographic holdings (maps, aerial photos, remote sensing images), 1989

5. Absolute increase in cartographic holdings, 1984-1989

6. Percentage increase in cartographic holdings, 1985-1989

7. A final, composite ranking, ex- 


\section{TABLE 3}

RANK, BY PERCENTAGE INCREASE IN MAP HOLDINGS, 1984-89

\begin{tabular}{lcll}
\hline \multicolumn{1}{c}{ Top Twenty } & \% Growth & University & Bottom Twenty \\
University & 1570 & University of Oregon & 4 \\
\hline University of Miami & 233 & University of Wisconsin, Madison & 3 \\
U.C. Riverside & 193 & Brown University & 1 \\
N. Carolina State & 111 & Harvard University & 0 \\
University of Maryland & 100 & Columbia University & 0 \\
Emory University & 85 & University of Oklahoma & 0 \\
Duke University & 59 & Vanderbilt University & 0 \\
Texas A\&M & 56 & University of Virginia & -5 \\
University of Texas, Austin & 47 & University of Michigan & -6 \\
University of Connecticut & 46 & Virginia Polytechnic Institute & -7 \\
University of Alabama & 43 & Boston University & -12 \\
Temple University & 39 & Colorado State University & -13 \\
University of Tennessee & 36 & Princeton University & -18 \\
Rice University & 35 & Ohio State University & -18 \\
University of Hawaii & 33 & Louisiana State University & -19 \\
Arizona State University & 31 & University of Cincinnati & -31 \\
University of New Mexico & 30 & Oklahoma State University & -33 \\
University of Arizona & 29 & Case Western Reserve & -35 \\
University of Utah & 29 & Wayne State University & -47 \\
U.C. San Diego & 26 & Washington State University & -62 \\
Rutgers University & & &
\end{tabular}

plained below, composed of variables 1-6

Absolute increase is an indicator of the willingness, and ability, of the library to acquire new material. Collections that score high in these categories are working to acquire new material (information) and to keep current as new maps and aerial photographs are produced.

Percentage increases tend to reward the smaller collections, since they are starting from a smaller base. Collections that score high in these categories are being more active in acquisition. It can be argued that smaller collections are aware of a small information base and are working on improving that base.

Table 1 presents the top and bottom twenty collections in terms of holdings of maps in 1989.

Table 1 does not present the same rankings in the second edition of the
Guide. Because of additional requests for information made for this article, more complete data are presented here than in the Guide.

Table 2 presents the top and bottom twenty collections by absolute increase in map holdings, 1984-1989.

As mentioned above, the increases in holdings for both the universities of Tennessee and Texas may be more related to data-collection issues than actual increases in size. Table 3 presents the top and bottom twenty collections by percentage increase in map holdings, 19841989.

The University of Miami has an extremely small collection (17,621 sheets), and the University of California, Riverside, is only 30,000 sheets. After those two, larger collections appear in the top twenty growth collections. Interestingly, some of the large collections, such as 
TABLE 4

RANK, BY TOTAL CARTOGRAPHIC HOLDINGS, 1989

Top Twenty

Bottom Twenty

\begin{tabular}{lrlr} 
University & Holdings & University & Holdings \\
\hline U.C. Santa Barbara & $4,075,000$ & Vanderbilt University & 100,000 \\
UCLA & 839,471 & Ohio State University & 96,000 \\
U.C. Berkeley & 660,437 & Temple University & 88,450 \\
University of Oregon & 628,000 & University of Pittsburgh & 86,457 \\
Cornell University & 595,400 & Mass. Institute of Technology & 83,004 \\
University of Illinois, Urbana & 592,614 & Brown University & 75,000 \\
University of Florida & 548,716 & University of Cincinnati & 74,930 \\
University of Georgia & 547,250 & Colorado State University & 34,899 \\
Indiana University & 521,425 & U.C. Riverside & 32,500 \\
Harvard University & 520,000 & Case Western Reserve & 32,500 \\
University of Minnesota & 487,929 & N. Carolina State University & 24,230 \\
University of Hawaii & 478,259 & Wayne State University & 22,000 \\
Louisiana State University & 472,225 & Rice University & 21,400 \\
Yale University & 385,503 & University of Miami & 17,621 \\
Kansas University & 376,698 & Tulane University & 15,000 \\
University of Tennessee & 359,199 & Washington State University & 15,000 \\
University of Wisconsin, Madison & 344,324 & Boston University & 11,050 \\
Washington University (St. Louis) & 339,112 & University of Southern California & 8,500 \\
University of Chicago & 339,100 & Rutgers University & 3,170 \\
Pennsylvania State University & 337,336 & U.C. Irvine & 1,180 \\
\hline Mean = & & &
\end{tabular}

Mean $=252,098$

STD $=439,190$

Harvard and Michigan, are static or actually shrinking.

Particular attention has been paid to the size and growth of the map portions of the collections. The map remains the primary information carrier and the largest proportion of most cartographic collections. Tables 4 and 5 are based on total cartographic holdings. Here the effect of collecting aerial photos and remote sensing imagery is apparent. The more technologically advanced collections rank higher in these listings.

The University of California, Santa Barbara, has a large map collection, but the large difference between it and secondranked UCLA results directly from U.C., Santa Barbara's large (2.5 million) aerial photo collection and its 1.2 million remote sensing images. Washington Uni-

versity in St. Louis is a bottom-twenty map collection, but the library there has acquired 250,000 remote sensing images to bring its collection into the top twenty in terms of total cartographic holdings.

The earlier comments about the growth rates of U.C., Santa Barbara and Washington University apply in table 6 as well.

As noted previously, the University of Miami has a very small collection, but some of the other large-growth collections are far from small. U.C., Santa Barbara's ranking is particularly impressive. Rank by percentage increase highlights the collections that are inactive or simply not collecting or reporting data.

\section{OVERALL RANKING}

The overall ranking was computed by assigning a rank to each institution for 
TABLE 5

RANK, BY INCREASE IN CARTOGRAPHIC HOLDINGS, 1984-89

\begin{tabular}{lrlr}
\hline \multicolumn{1}{c}{ Top Twenty } & & & \multicolumn{2}{c}{ Bottom Twenty } \\
University & Growth & University & Growth \\
\hline U.C. Santa Barbara & $3,475,000$ & Rutgers University & 669 \\
Cornell University & 434,400 & U.C. Irvine & 579 \\
University of Hawaii & 368,659 & Columbia University & -1 \\
Washington University (St. Louis) & 255,896 & University of Oklahoma & -1 \\
UCLA & 222,500 & Vanderbilt University & -1 \\
Purdue University & 179,500 & Boston University & $-1,450$ \\
Kansas University & 133,166 & Colorado State University & $-5,102$ \\
University of Alabama & 131,400 & SUNY Albany & $-8,001$ \\
University of Texas, Austin & 120,167 & University of Virginia & $-11,750$ \\
U.C. Berkeley & 114,376 & University of Michigan & $-16,500$ \\
University of Tennessee & 101,752 & Case Western Reserve & $-17,501$ \\
University of Illinois, Urbana & 86,570 & Brigham Young University & $-18,914$ \\
University of Maryland & 80,490 & Wayne State University & $-20,020$ \\
University of Oregon & 73,823 & Ohio State University & $-22,462$ \\
University of Georgia & 65,150 & Washington State University & $-25,030$ \\
University of Connecticut & 62,999 & University of Cincinnati & $-37,570$ \\
University of Chicago & 54,600 & Va. Polytechnic Institute & $-43,400$ \\
Duke University & 52,950 & Oklahoma State University & $-56,738$ \\
Emory University & 49,999 & Princeton University & $-66,086$ \\
University of Arizona & 49,661 & Louisiana State University & $-89,275$ \\
\hline Mean = & & &
\end{tabular}

Mean $=73,945$

$\mathrm{STD}=366,410$

each of the six variables presented above. A score was then assigned based on the reciprocal of that rank, using 100 as a base. In other words, if a collection ranked first on a given variable, it received 99 points. If the collection ranked 30 th, it received 70 points (100-30), and so forth. The overall ranking was computed by adding the six variable scores and dividing by six. A perfect score would have been $99 . .^{18}$ The numerical scores obtained by this process are statistically meaningless. They serve only to present a rank order of the collections and hence are not reported.

Any ranking system will have its critics. This one attempts to reward collections that have a large information content (i.e., large holdings), are active in acquiring new holdings, and are ac- tive in acquiring technologically advanced cartographic formats. The rankings are based on the theory that size equals information content and, perhaps, quality. The rankings do not tell us anything about usage, effectiveness of collection development, or other variables explicitly addressed by the PLA and ACRL systems mentioned above.

\section{TESTING THE HYPOTHESIS}

Readers familiar with the ARL composite rankings will note that the rankings presented in table 7 differ considerably from those published by the ARL. Some very highly ranked ARL collections fair poorly in this study. The University of Wisconsin, Madison, for instance, which ranks 13 th in the $A R L$, ranks 58 th in this study. The top-rated collection in this 
TABLE 6

RANK, BY PERCENTAGE INCREASE IN CARTOGRAPHIC HOLDINGS, 1984-89

\begin{tabular}{|c|c|c|c|}
\hline \multicolumn{2}{|c|}{ Top Twenty } & \multicolumn{2}{|c|}{ Bottom Twenty } \\
\hline University & \% Growth & University & $\%$ Growth \\
\hline University of Miami & 1,568 & Brown University & 1 \\
\hline U.C. Santa Barbara & 579 & Univ. of Wis., Madison & 1 \\
\hline University of Hawaii & 336 & Harvard University & 1 \\
\hline Washington University & 307 & "Columbia University & -0 \\
\hline Cornell University & 269 & University of Oklahoma & -0 \\
\hline U.C. Riverside & 256 & "Vanderbilt University & -0 \\
\hline North Carolina State & 193 & University of Virginia & -5 \\
\hline Purdue University & 119 & University of Michigan & -6 \\
\hline University of Maryland & 111 & Brigham Young University & -8 \\
\hline Emory University & 99 & Boston University & -11 \\
\hline U.C. Irvine & 96 & Colorado State University & -12 \\
\hline University of Alabama & 94 & Louisiana State University & -15 \\
\hline Duke University & 85 & Princeton University & -18 \\
\hline University of Connecticut & 62 & Ohio State University & -18 \\
\hline Texas A\&M & 58 & Oklahoma State University & -25 \\
\hline University of Texas, Austin & 57 & Va. Polytechnic Institute & -26 \\
\hline Kansas University & 54 & University of Cincinnati & -33 \\
\hline Temple University & 43 & Case Western Reserve & -35 \\
\hline Arizona State University & 40 & Wayne State University & -47 \\
\hline University of Tennessee & 39 & Wa. State University & -62 \\
\hline
\end{tabular}

* -0 means growth was negative, but less than $1 \%$.

study, the University of California, Santa Barbara, is ranked 46th by ARL.

This study assumes that size of collection is a strong indicator of the information content of the collection.

The basic issue being investigated in this study is whether cartographic materials are stepchildren in ARL libraries. The method employed is to develop a ranking of ARL cartographic materials collections that is similar conceptually to the familiar ARL rankings largely based on size and growth rate of book and serial holdings. If cartographic collections receive the same emphasis in collection development enjoyed by book and serial collections, the ARL rankings and the ranking produced by this study should be closely related.

The statistical technique selected to measure the relationship between the two rankings is Spearman's rank order coefficient, or rho. Spearman's rho $\left(r_{s}\right)$ is commonly used to compare matchedpair rankings. ${ }^{19}$ Spearman's rho requires that each set of ranks be ordinal-level data, so the ARL library index list was matched to the eighty-eight institutions considered in this study. That is, they were ranked 1-88, rather than being ranked within the total ARL population.

Spearman's rho produces a correlation coefficient that measures the strength of the relationship between the two rankings. Rho can vary from -1 to +1 , where 1 expresses a perfect negative or positive correlation. One statistician has suggested the following guidelines 
TABLE 7

RANK, BASED ON COMPOSITE SIZE/GROWTH RANKINGS, 1989

\begin{tabular}{|c|c|c|c|}
\hline Rank & University & Rank & University \\
\hline 1 & U.C. Santa Barbara & 39 & University of Kentucky \\
\hline 2 & University of Texas, Austin & 40 & University of Nebraska \\
\hline 3 & UCLA & 41 & University of Massachusetts, Amherst \\
\hline 4 & University of Tennessee & 42 & Dartmouth University \\
\hline 5 & Cornell University & 43 & Yale University \\
\hline 6 & University of Illinois, Urbana & 44 & U.C. Davis \\
\hline 7 & University of Alabama & 45 & University of Miami \\
\hline 8 & U.C. Berkeley & 46 & Michigan State University \\
\hline 9 & University of Hawaii & 47 & Northwestern University \\
\hline 10 & Kansas University & 48 & North Carolina State \\
\hline 11 & University of Chicago & 49 & Harvard University \\
\hline 12 & University of Maryland & 50 & Florida State University \\
\hline 13 & University of Arizona & 51 & Johns Hopkins University \\
\hline 14 & Purdue University & 52 & North Carolina, Chapel Hill \\
\hline 15 & U.C. San Diego & 53 & University of Missouri \\
\hline 16 & University of Connecticut & 54 & Brigham Young University \\
\hline 17 & Southern Illinois University & 55 & Iowa State University \\
\hline 18 & University of Georgia & 56 & University of Pennsylvania \\
\hline 19 & Pennsylvania State University & 57 & University of Wisconsin, Madison \\
\hline 20 & Texas A\&M & 58 & SUNY Buffalo \\
\hline 21 & Duke University & 59 & University of Michigan \\
\hline 22 & University of Florida & 60 & University of Delaware \\
\hline 23 & Arizona State University & 61 & Rice University \\
\hline 24 & University of Iowa & 62 & Syracuse University \\
\hline 25 & Stanford University & 63 & SUNY Stony Brook \\
\hline 26 & Emory University & 64 & Notre Dame \\
\hline 27 & University of New Mexico & 65 & University of Pittsburgh \\
\hline 28 & University of Utah & 66 & Rutgers University \\
\hline 29 & University of Washington & 67 & Louisiana State University \\
\hline 30 & Washington University (St. Louis) & 68 & University of Colorado \\
\hline 31 & University of Minnesota & 69 & Columbia University \\
\hline 32 & Indiana University & 70 & University of Virginia \\
\hline 33 & University of South Carolina & 71 & Princeton University \\
\hline 34 & University of Oregon & 72 & Tulane University \\
\hline 35 & Temple University & 73 & U.C. Irvine \\
\hline 36 & U.C. Riverside & 74 & Massachusetts Institute of Technology \\
\hline 37 & Georgia Tech & 75 & University of Oklahoma \\
\hline 38 & Kent State University & 76 & University of Southern California \\
\hline
\end{tabular}


TABLE 7

RANK, BASED ON COMPOSITE SIZE/GROWTH RANKINGS, 1989 (cont.)

\begin{tabular}{clcl}
\hline Rank & University & Rank & University \\
\hline 77 & Brown University & 83 & Boston University \\
78 & Vanderbilt University & 84 & Case Western Reserve \\
79 & Oklahoma State University & 85 & University of Cincinnati \\
80 & Virginia Polytechnic Institute & 86 & Wayne State University \\
81 & Colorado State University & 87 & Washington State University \\
82 & Ohio State University & & \\
\hline
\end{tabular}

for interpreting values between 0 and 1 :

$\begin{aligned} r \text { value } & \text { Interpretation } \\ <.20 & \begin{array}{c}\text { Slight, almost negligible } \\ \text { relationship }\end{array}\end{aligned}$

$.20-.40$ Low correlation, definite, but small relationship

.40-.70 Moderatecorrelation; substantial relationship

.70-.90 High correlation; marked relationship

.90-1.0 Very high correlation; very dependable relationship ${ }^{20}$

The hypothesis being tested involves the strength of the relationship between the two rankings. Statistical significance is not an issue in this situation because sampling error is not involved. The question is: Is the observed $r_{s}$ strong enough to dispute the idea that cartographic materials are stepchildren in the matter of size and growth of the collection?

The ARL rankings and the rankings in this study were found to correlate at $\mathrm{r}_{\mathrm{s}}=$ 0.31 . This means that there is a positive relationship between the two ranking systems. The strength of the relationship, however, falls in the low, or weak category in the scheme noted above. ${ }^{21} \mathrm{An}$ observed $r_{s}$ of 0.31 suggests that the relationship between the ARL rankings and those obtained in this study is low. This suggests that little consensus about the importance of the cartographic format exists within the ARL libraries. Some of the libraries at the top of the ARL list-Texas, UCLA, Cornell, and the University of Illinois, Urbana, for example-seem to place cartographic materi- als on approximately the same level of importance as other formats. Other top ARL collections-Yale, Harvard, and Columbia being the notable examplesdo not seem to value cartographic material as much as other formats.

\section{SUMMARY AND CONCLUSIONS}

The map collections of the ARL libraries have been measured and ranked according to a composite index based on size and growth figures for both maps and other cartographic formats. The rankings reflect not only absolute collection size, but also the rate of increase in all cartographic formats. The rankings should provide a useful measure for comparisons among ARL libraries interested in one measure of their collections and also provide possible benchmark data for non-ARL libraries to consider. Given the low correlation between ARL rankings and rankings in this study, it seems that Wilmer Hall's comment about map collections as stepchildren is as correct now as it was in 1925 .

It is hoped that this study will prompt ARL chief collection development officers to discuss the cartographic format. Clearly, at a number of institutions the relationship between effort expended in collection development for books and serials and that for cartographic materials is insignificant.

Equally clear from this study is that individuals in charge of map collections at ARL institutions have work to do in improving the nature of the data they are reporting. As was noted above, such basic elements as collection size appear to be estimates in all too many cases. Other data elements need similar atten- 
tion. Reporting on number of staff was so inconsistent that the editor of the Guide considered eliminating the category from the published version. ${ }^{2}$ The ARL libraries fare no better than any others in this category.

The collection index is limited conceptually in that it does not address issues of user interaction with the collection or the relationship of the cartographic collection with the rest of the library or parent institution. Because of limits im- posed by institutional reporting of data, more sophisticated measures, such as those suggested in Output Measures or Measuring Academic Library Performance, cannot be generated for all ARL map collections at this time. ${ }^{23}$ Future studies drawn from data in the two editions of the Guide will attempt to develop measures related to user-collection interaction, facilities, and collection-institution interaction for the subset of ARL libraries with sufficiently complete data.

\section{REFERENCES AND NOTES}

1. Wilmer L. Hall, "A Classification for Maps," Library Journal 50:257-59 (Mar. 15, 1925).

2. Mark Monmonier and George A. Schnell, Map Appreciation (Englewood Cliffs, N.J.: Prentice Hall, 1988), p.3-5.

3. For instance, Map Collections in the United States and Canada (New York: Special Libraries Association, 1978) listed 345 map collections in academic institutions. Both editions of the Guide to U.S. Map Resources contain considerably more academic map collections than that. Of special significance to the spread of map collections has been the inclusion of U.S. Geological Survey and other federal mapping agency products into the U.S. Government Printing Office depository system in the mid-1980s.

4. Stanley D. Stevens, "Map Librarianship-Today and Tomorrow," Drexel Library Quarterly 9:3-14 (Oct. 1973).

5. David A. Cobb, "Map Librarianship in the U.S.: An Overview," Wilson Library Bulletin 60:14-16 (Oct. 1985). The Wilson Library Bulletin piece was largely based on Cobb's "Introduction," Guide to U.S. Map Resources, 1st ed. (Chicago: American Library Assn., 1986), p.ix-xvi.

6. David A. Cobb, ed., "Introduction," Guide to U.S. Map Resources, 2d ed. (Chicago: American Library Assn., 1990), p.ix-xvii.

7. Susan A. Cady, "The Electronic Revolution in Libraries: Microfilm Deja Vu?" College \& Research Libraries 51:374-86 (July 1990).

8. Vernon C. Palmour and others, A Planning Process for Public Libraries (Chicago: American Library Assn., 1980); Douglas L. Zweizig and Eleanor Jo Rodger, Output Measures for Public Libraries (Chicago: American Library Assn., 1982).

9. Nancy A. Van House, Beth T. Weil, and Charles R. McClure, Measuring Academic Library Performance: A Practical Approach (Chicago: American Library Assn., 1990).

10. The ARL index is based on the following variables: number of volumes held, number of volumes added during the previous fiscal year, number of current serials, total expenditures, and size of staff. For a brief description of the ARL index, see ARL, ARL Statistics, 1982-83 (Washington, D.C.: ARL, 1984) p.27-28. For a complete description see Kendon Stubbs, The ARL Library Index and Quantitative Relationships in the ARL (Washington, D.C.: ARL, 1980). ARL composite rankings used in this study are drawn from The Chronicle of Higher Education, "Almanac" supplement, 37:27 (Sept. 5, 1990).

11. Charles A. Seavey, "Collection Development for Government Map Collections," Government Publications Review, 8A:17-29 (1981).

12. U.S. Geological Survey, Los Griegos, New Mexico, 1:24,000 scale topographic map (Reston, Va.: The Survey, 1960, photorevision, 1972).

13. David A. Cobb, Guide (1986, 1990).

14. Cobb, Guide (1986), p.x.

15. The instrument is included as an appendix in both editions of the Guide.

16. Both collections have fewer than 1,000 maps. However, they are both in the Washington, D.C., area and have access to the largest concentration of cartographic holdings in the country: the collections of the Library of Congress and the National Archives. 
17. An ARL collection under the author's care went from an estimated size of 120,000 sheets to an actual count of 85,061 . This is not an uncommon phenomenon, which certainly indicates that the ARL libraries, and probably all collections, need to establish better record-keeping procedures than currently employed.

18. The ARL index used to produce overall rankings based on the variables noted in note 10 is considerably more complex in construction than the method employed here. The ARL has had years of experience in collecting and refining the reliability of its data. In this researcher's judgment the data presented in the Guide are simply not reliable enough to be subjected to the rigorous statistical manipulations employed by the ARL.

19. Richard C. Sprinthall, Basic Statistical Analysis, 2d ed. (Englewood Cliffs, N.J.: Prentice Hall, 1987), p.200-202.

20. Joy Paul Guilford, Fundamental Statistics in Psychology and Education, 3d ed. (New York: McGraw-Hill, 1956), p.145.

21. Interpretation of correlation tests is subject to considerable debate. Obtaining a statistically significant correlation with Spearman's rho, or the more rigorous Pearson's $r$, is largely a function of the size of $\mathrm{N}$ and need only be employed when samples, rather than populations, are being tested. The interpretation of the strength of relationship presented here is a conservative one. Guilford's scheme is usable, but problematic, particularly in the middle interval. Given the data employed in this study and general approach to correlational statistics, this researcher would not describe correlations as "strong" until values above $\mathrm{r}_{\mathrm{s}}=.75$ are obtained. Others are free to interpret the obtained value as they choose.

22. The 1990 edition of the Guide, in both the published version and a prepublication version in the possession of this author, carries statements to the effect that staff data were not included because of reliability problems (see page xv, published version). The published version does report staffing levels for most collections.

23. For instance, many institutions either do not circulate cartographic materials or fail to collect (or report) such data if they do. 